\title{
Prevalence and phylogenetic analysis of hepatitis E virus in pigs in Vietnam
}

\author{
Hu Suk Lee ${ }^{1^{* \dagger}} \mathbb{D}$, Duy Tung Dao ${ }^{2 \dagger}$, Vuong Nghia Bui ${ }^{2}$, Ngoc Anh Bui ${ }^{2}$, Thanh Duy Le ${ }^{2}$, Hung Nguyen-Viet ${ }^{1}$,
} Delia Grace ${ }^{3,4}$, Krishna K. Thakur ${ }^{5}$ and Katsuro Hagiwara ${ }^{6^{*}}$

\begin{abstract}
Background: Hepatitis E virus (HEV) is a zoonotic disease and has been reported around the world. The main objective of this study was to evaluate the sero-prevalence and phylogenetic analysis of HEV in Vietnam. Pig blood and fecal pooled samples were collected to assess the prevalence of HEV. We assessed the true prevalence (TP) of HEV from apparent prevalence (AP) by taking into account the sensitivity and specificity of diagnostic tests using a Bayesian approach. For phylogenetic analysis, the data compared with worldwide HEV reference strains including all eight genotypes (G1-G8) which were identified in previous study.

Results: A total of 475 sera and 250 fecal pooled samples were collected at slaughterhouses and pig farms from five provinces, in Viet Nam. Overall, the sero-AP of HEV was 58.53\% (95\% confidence interval: 53.95-62.70) while the sero-TP was slightly higher (65.43, 95\% credible interval: 47.19-84.70). In terms of pooled samples, overall, the RNAAP was 6.80\% (95\% confidence interval: 4.01-10.66). One strain in Hanoi, two strains in Dak Lak, seven strains in An Giang, four strains in Son La and two strains in Nghe An were isolated. The phylogenetic tree demonstrated that 19 Vietnamese strains were clustered into HEV 3 and 4.

Conclusions: This study provided evidence that HEV is circulating in domestic pigs in Vietnam. From a public health perspective, it is very important to raise public awareness for high-risk groups (e.g. slaughterhouse workers, pig traders, farmers and market sellers) who have more opportunities to come in contact with pig and contaminated meats.
\end{abstract}

Keywords: Vietnam, pigs, Hepatitis E, prevalence, phylogenetic analysis

\section{Background}

Hepatitis E virus (HEV) is one of the important zoonotic diseases with a worldwide distribution, and it is commonly reported in Asia, Africa and Latin America [1]. Annually, 20 million HEV infections are reported around the world, with cases in South and Southeast Asia accounting for $60.6 \%$ or the total and deaths

\footnotetext{
* Correspondence: H.S.Lee@cgiar.org; k-hagi@rakuno.ac.jp

${ }^{\dagger}$ Hu Suk Lee and Duy Tung Dao contributed equally to this work.

'International Livestock Research Institute (ILRI), Regional Office for East and

Southeast Asia, Room 301-302, B1 Building, Van Phuc Diplomatic Compound,

298 Kim Ma Street, Ba Dinh District, Hanoi, Vietnam

${ }^{6}$ School of Veterinary Medicine, Rakuno Gakuen University, 582 Bunkyodai, Ebetsu, Hokkaido 069-8501, Japan

Full list of author information is available at the end of the article
}

$64.7 \%[1,2]$. The virus has been classified into the Orthohepevirus genus within the Hepeviridae family [3]. Currently, at least eight genotypes of HEV have been identified $[4,5]$. Five genotypes (HEV $1-4$ and 7) are transmitted from human to human primarily via the fecal-oral route due to fecal contamination of drinking water $[1,6]$. In general, these genotypes are commonly circulating in the areas with poor sanitation and low socio-economic status. Genotypes 3 and 4 have been considered a foodborne zoonotic disease that is commonly transmitted to humans by ingestion of raw or undercooked meat products (e.g. pig, wild boar and deer), drinking of animal milk (e.g. camels) and via direct exposure to animal feces [6-8].

(c) The Author(s). 2020 Open Access This article is licensed under a Creative Commons Attribution 4.0 International License, which permits use, sharing, adaptation, distribution and reproduction in any medium or format, as long as you give appropriate credit to the original author(s) and the source, provide a link to the Creative Commons licence, and indicate if changes were made. The images or other third party material in this article are included in the article's Creative Commons licence, unless indicated otherwise in a credit line to the material. If material is not included in the article's Creative Commons licence and your intended use is not permitted by statutory regulation or exceeds the permitted use, you will need to obtain permission directly from the copyright holder. To view a copy of this licence, visit http://creativecommons.org/licenses/by/4.0/ The Creative Commons Public Domain Dedication waiver (http://creativecommons.org/publicdomain/zero/1.0/) applies to the data made available in this article, unless otherwise stated in a credit line to the data. 
Previous studies have isolated HEV 3 and 4 from pigs in the United States, the United Kingdom, France, South Korea, China and Japan [9-14]. Phylogenetic study provided evidence that the swine-origin HEV and human HEV isolates had a close association, suggesting that pigs play an important role in the transmission of the virus to humans [15].

In Southeast Asia, some studies revealed the transmission of HEV 3 and 4 from animals to humans providing evidence of circulating HEV in pigs [16-18].

In Vietnam, the first HEV outbreak in humans was reported in 1994 along the river bordering Cambodia in the southwestern part [19]. One study showed that HEV is circulating in pigs (prevalence: $19.1 \%$ in fecal samples and $8.2 \%$ in rectal samples) while humans showed $31.7 \%$ seroprevalence [20]. In addition, a recent study in Vietnam found that pig farmers, slaughterhouse workers and pork meat retailers had high seroprevalence compared to unexposed groups [21]. Also, it showed that HEV was detected from liver tissues in pigs.

To our knowledge, no studies have been conducted to evaluate the true prevalence (TP) of HEV in pigs in Vietnam. TP is the proportion of animals which have a disease in the population while apparent prevalence (AP) is the proportion of animals testing positive by a diagnostic test. If sensitivity and specificity of diagnostic test are less than $100 \%$, estimated prevalence is biased. We therefore used a Bayesian analysis to estimate the TP from AP. The main objective of this study was to assess the TP and phylogenetic analysis of HEV in pigs from 5 provinces in Vietnam.

\section{Results}

\section{Estimated true prevalence of HEV}

A total of 475 sera samples were collected at slaughterhouses from five provinces. Overall, the sero-AP of HEV was $58.53 \%$ (95\% CI: $53.95-62.70)$ while the sero-TP was slightly higher $(65.43$, 95\% credible interval: $47.19-$ 84.70) (Table 1). Dak Lak had the highest seroprevalence followed by Nghe An and Son La whereas An Giang and Hanoi showed the lowest sero-prevalence. Overall, the sero-TPs were higher than the sero-APs except for An Giang and Hanoi provinces. BrooksGelman-Rubin (BGR) plots displayed that all chains converged for sero-TPs (S1 Fig).

A total of 250 pooled fecal samples were collected at farm level. Overall, the RNA-A was estimated at $6.8 \%$ (95\% CI: 4.01-10.66\%) (Table 2). An Giang had the highest RNA-AP followed by Son La while Hanoi showed the lowest RNA-AP. There were no statistically significant differences in sero-prevalence between female (79.10, 95\% CI: 73.74-83.81) and male (79.23, 95\% CI: 73.06-84.54) pigs as the confidence intervals of the groups were overlapping.

\section{Phylogenetics analysis of HEV}

The $348 \mathrm{bp}$ HEV ORF2 nucleotide sequence was successfully obtained from fecal samples. A total of 19 Vietnamese strains were isolated in samples, including 1 strain in Hanoi, 5 strains in Dak Lak, 7 strains in An Giang, 4 strains in Son La and 2 strains in Nghe An (Fig. 1). All 19 nucleotide sequences of HEV ORF2 have been deposited on GenBank (accession number MT670024-MT670042). The phylogenetic tree demonstrated that 19 Vietnamese strains were clustered into HEV 3 and 4 among 8 genotypes. Genotype 3 is dominant including 17 strains divided into two sub-genotypes 3 (15 strains (MT670024-MT670034, MT670037MT670039, MT670042) belonged to sub-genotype 3a and 2 strains (MT670035, MT67036) clustered into subgenotype 3d). Two remaining strains (MT670040, MT670041) were identified from Son La province were clustered into HEV 4, sub-genotype 4b. These strains showed a close relationship with the strain isolated from a monkey in China.

Based on the host phylogenetic tree, it is assumed that HEVs are human in origin (Fig. 2). Humans are the main reservoir that spread the virus to other animals including swine, wild boar, goat, and camel. However, humans can also be infected with HEVs from swine and camel. Swine play an important role in transmitting the HEVs to mongoose, monkey, wild boar and in contaminating the environment (seawater). In addition, the host

Table 1 Sero-apparent prevalence with $95 \% \mathrm{Cl}^{\mathrm{a}}$ and sero-true prevalence with 95\% credible interval for hepatitis $\mathrm{E}$ virus in sera samples in pig slaughterhouses

\begin{tabular}{llll}
\hline Province (no.) & Positive samples & AP (\%) with 95\% Cl & TP (\%) $)^{\mathrm{b}}$ with 95\% credible interval \\
\hline An Giang (95) & 20 & $21.05(13.36-30.62)$ & $8.04(0.02-29.56)$ \\
Dak Lak (95) & 86 & $90.53(82.78-95.58)$ & $97.24(86.39-99.99)$ \\
Hanoi (95) & 26 & $27.37(18.72-37.48)$ & $15.21(0.09-38.66)$ \\
Nghe An (95) & 75 & $78.95(69.38-86.64)$ & $93.19(72.39-99.99)$ \\
Son La (95) & 71 & $74.74(64.78-83.09)$ & $90.57(67.09-99.98)$ \\
Total (475) & 278 & $58.53(53.95-62.70)$ & $65.43(47.19-84.70)$ \\
\hline
\end{tabular}

${ }^{\mathrm{a}} \mathrm{Cl}$ confidence interval; ${ }^{\mathrm{b}}$ Median value was recorded 
Table 2 RNA-apparent prevalence with $95 \% \mathrm{Cl}^{a}$ for hepatitis E virus in fecal pooled samples in pig farms (2 fecal pooled samples / farm)

\begin{tabular}{lll}
\hline Province (no.) & Positive pooled samples & RNA-apparent prevalence with 95\% Cl \\
\hline An Giang (50) & 6 & $12.00(4.53-24.31)$ \\
Dak Lak (50) & 3 & $6.00(1.25-16.55)$ \\
Hanoi (50) & 1 & $2.00(0.05-10.65)$ \\
Nghe An (50) & 3 & $6.00(1.25-16.55)$ \\
Son La (50) & 4 & $8.00(2.22-19.23)$ \\
Total (250) & 17 & $6.80(4.01-10.66)$ \\
\hline
\end{tabular}

${ }^{a} \mathrm{Cl}$ confidence interval

phylogenetic tree indicated the HEVs can be transmitted from goats to sheep and from wild boar to deer.

\section{Discussion}

A large national study was implemented to evaluate the prevalence and molecular characteristics of HEV in pigs across Viet Nam. Overall, our anti-HEV IgG prevalence (approximately 58\%) was very similar to other studies in Germany (47\%), Italy (50.2\%), Japan (56\%), Philippines (50.3\%) and Laos (51.2\%) [22-26]. Some studies showed a higher seroprevalence of IgG as pigs grow older [27, 28]. However, we were not able to evaluate this because sera samples were obtained from fattening pigs (6-8 months old and weighing 60-120 kg) at slaughterhouses. Interestingly, sero-TPs of three provinces (Dak Lak, Nghe An and Son La) was estimated more than 90\%, suggesting a high potential zoonotic transmission to humans. Overall, the RNA-positive rate $(6.8 \%)$ in pooled fecal samples was very similar to other studies in Laos (11.5\%), Philippines (7.4\%) and Thailand (1.27-2.9\%) $[18,22,29,30]$.

Previous studies have provided evidence that there was an epidemiological association between consumption of pork meat and HEV cases [31, 32]. In Vietnam, most of the farmers in rural areas raise pigs in backyards with poor sanitary conditions. They have more opportunities to come in contact with pigs and pig waste. In addition, it is very common that local people consume uncooked pork, livers meats, sausages, unwashed vegetables and insufficiently treated drinking water. Therefore, it might be possible that people who are exposed to pig and pork meats are at an increased risk of HEV transmission [33]. Further studies are needed to evaluate whether this exposure route poses a public health concern as well as to better understand the human behavior for preventing HEV infections.

The Bayesian maximum clade credibility (MCC) host discrete traits tree provided information about the transmission of HEVs between humans, swine and other animals. Humans are the main reservoir/ maintenance host of HEV but pigs are a well-known as a reservoir of HEV that transmit the virus to humans. In addition, the host phylogenetic tree indicated that HEV can be transmitted from camel to humans [8]. This tree showed that HEV genotypes 3 and 4 are considered zoonotic viruses, and the new HEV genotype 7 can be transmitted from camel to humans. Therefore, HEVs are now recognized as an emerging zoonotic agent.

We found that both genotypes HEV 3 and 4 were detected in domestic pigs across the country which was in line with other Asian countries [34-36]. Most of them $(15 / 19)$ were classified into the existing genotype 3 which is the commonly detected subtype in Asia (including Japan, South Korea and Philippines) [22, 37, 38]. The two remaining Vietnamese HEV strains that were isolated in An Giang, were clustered into sub-genotype 3d with Cambodia and Taiwan strains. The HEV 4 (subgenotype $4 \mathrm{~b}$ ) was only detected in Son La province which is on the borders with Laos $[18,34,39]$. Therefore, it might provide evidence that this type is circulating in these areas. The proportion of minorities (e.g. Thai and H'Mong) is relatively higher than areas in Son La province (the major ethnic group is Kinh, occupying $85.7 \%$ of the population) [40]. In general, ethnic minorities are less educated and incomes than the Kinh group, which are associated with limited awareness of hygiene and food safety in Vietnam [41]. In addition, other studies found that highly educated people had a better knowledge of food safety as opposed to those with low education [42, 43]. Ethnic minorities may benefit from efforts to enhance public awareness of food safety and disease prevention. Further epidemiological study needs to be conducted to establish a transmission link between pigs and humans in Son La province. Also, one recent study showed that the HEV seroprevalence was higher among individuals occupationally exposed to pig and pork products [21]. Therefore, the human health impact of HEV should be properly defined to establish appropriate interventions.

The main limitation of our study was that our blood and fecal samples may not be representative because blood samples were only collected at slaughterhouses and were disproportionally collected depending on the number of pigs at each farm. Large and medium scale 


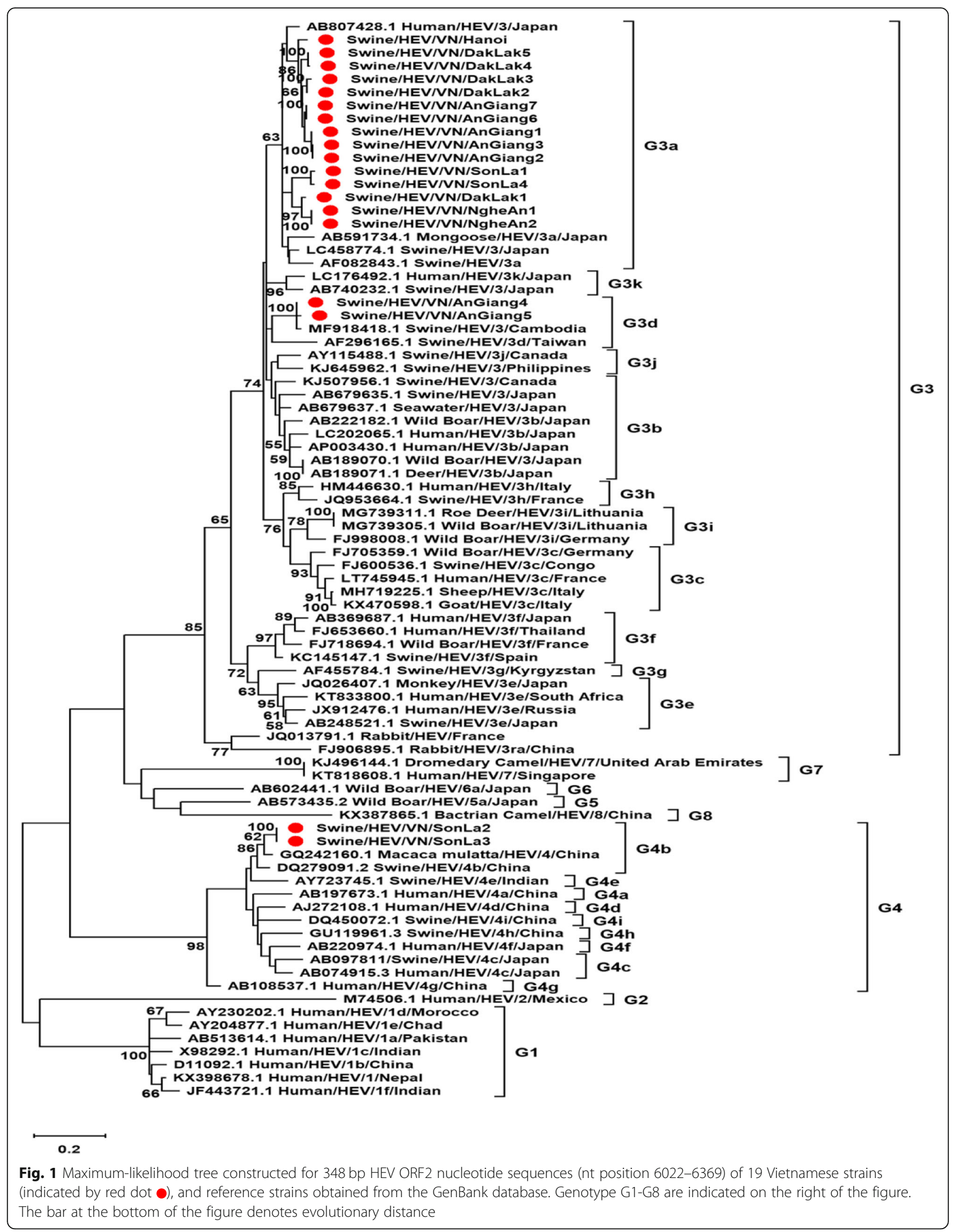




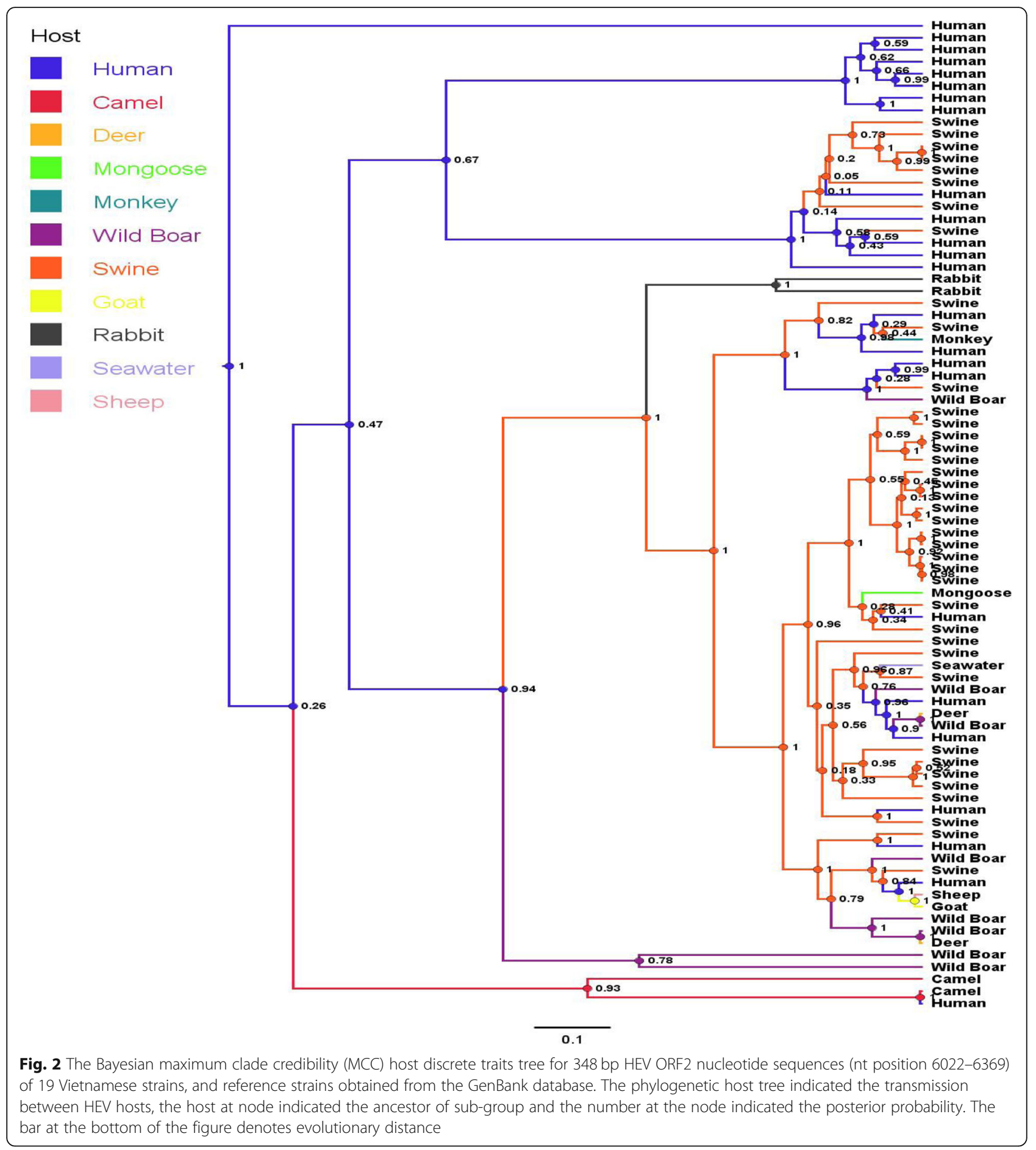

farmers were not willing to participate (mainly for biosecurity reasons) in our study. Although, our pig samples were not representative of the general population, we think that our findings provide valuable information on the epidemiology of HEV in Vietnam. It could be possible that the TP of HEV may be under/overestimated due to a random error with our measuring facilities. In addition, our prior estimates for the sensitivity and specificity of the ELISA test were obtained from our experiment and therefore, we are not clear which estimates are suitable for the Vietnamese context. We conducted some simulations to explore what happens with $N=80$, 70,60 , etc. out of 95 samples. There was a large discrepancy between the AP and TP as the positive cases 
decreased. The main reason was that when data (likelihood) is weak, posterior estimates are strongly influenced by priors [44].

A Bayesian method provides a chance to integrate prior information with observed data, which is useful for estimating values for both prevalence and diagnostic characteristics of tests [45]. If a diagnostic test has less than $100 \%$ sensitivity and specificity, the estimated prevalence is likely to be biased. Therefore, a Bayesian approach was applied to estimate the TP from AP. Overall, Bayesian models are very susceptible replying on the priors, so we employed a Jeffreys prior to reduce the impact of prior to the posterior distribution as there was no prior information for HEV prevalence in the study sites. This study was the first attempt to evaluate the TP for HEV in Vietnam and demonstrates how a Bayesian analysis can be applied to better estimate the prevalence of diseases.

\section{Conclusion}

This study provided evidence that HEV is circulating in domestic pigs in Vietnam. Further study is necessary to evaluate the possible transmission from pigs and environmental risk factors to humans. From a public health perspective, it is very important to raise public awareness for high-risk groups (e.g. slaughterhouse workers, pig traders, farmers and market sellers) who may have more opportunities to come in contact with pig and contaminated meats. Therefore, a national surveillance system and practical guidelines for proper handling of meat products needs to be established for disease control and prevention.

\section{Methods}

\section{Study locations and sampling}

Pig blood samples from previous cross-sectional survey [46] were used to estimate the sero-prevalence of HEV at the National Institute of Veterinary Research (NIVR) in Hanoi. Sera samples from fattening pigs (6-8 months old and weighing $60-120 \mathrm{~kg}$ ) were randomly collected from the jugular vein at slaughterhouses in five provinces (An Giang, Dak Lak, Hanoi, Nghe An, Son La) (Fig. 3). For our study, 95 sera samples were randomly selected from each province (385 samples / province). Fecal pooled samples were collected in 25 farms/province from 2018 to 2019. Two fecal pooled samples of a minimum of $2 \mathrm{~g}$ were collected in a sterile plastic container at each farm and were kept at $-20^{\circ} \mathrm{C}$ until transportation. This study was approved by the Hanoi Medical University Institutional Review Board (IRB: no. 00003121), Vietnam.

\section{Laboratory analysis} Serum examination

Anti-HEV antibodies were detected by enzyme-linked immunosorbent assay (ELISA) using HEV genotype 3 -derived VLP as an antigen. For the detection of antigen bound IgG, anti-pig IgG antibody-HRP (Bethyl Laboratories Inc. TX. USA) conjugate was applied as a secondary antibody. The serum samples were diluted 1:100 with PBS containing $0.05 \%$ Tween 20, and $10 \%$ of Block Ace (DS Pharma Promo Co. Ltd. Osaka, Japan), and incubated for $1 \mathrm{~h}$ at room temperature. After the secondary antibody reactions, $50 \mu \mathrm{l}$ of TMB (3,3',5,5' -tetramethylbenzidine) (Kirkegaard \& Perry Laboratories Inc., Baltimore, MD, USA) was added, and after a 10-min incubation at room temperature, $50 \mu \mathrm{l}$ of $2 \mathrm{M}$ sulphuric acid was added to stop the reactions. The optical density (OD) value at $450 \mathrm{~nm}$ was measured by a microplate spectrophotometer (Thermo Fisher Scientific Inc. USA). The Index value was calculated from the OD value obtained by ELISA as follows.

$$
\text { Index value : } \frac{\text { Sample OD - Control OD }}{\text { Positive OD - Control OD }} 100(\%)
$$

The cut off value was set at 0.295 by calculating the average value +2 standard deviation of negative samples $(n=5)$. As a result, the sensitivity and a specificity for the test were $90.0 \%$ (95\% CI: $68.30-98.77$ ) and $91.67 \%$ (95\% CI: 73.0-98.97) based on the test results of 20 experimentally infected and 24 Negative pigs.

\section{RNA extraction and detection of HEV by RT-PCR}

A portion of fecal samples was suspended with PBS and centrifuged at $5000 \mathrm{rpm}$ for $5 \mathrm{~min}$, and $250 \mathrm{ul}$ of the supernatant was used for RNA extraction. The RNA was extracted using the RNA purification kits via the Directzol $^{\text {Tw }}$ (Zymo Research, CA. USA) method. One-step RTPCR using HEV ORF2 as a target region was performed using the extracted RNA as a template. The QIAGEN One-Step RT-PCR Kit (QIAGEN) was used for RT-PCR master mix using $5 \mu \mathrm{l}$ of RNA as a template, and $10 \mu \mathrm{M}$ each primers Her F1: 5'-AATTATGCYCAGTAYCGR GTTG-3' and Her R1: 5'-CCCTTRTCYTGCTGMG CATTCTC-3' [9]. The reaction conditions were reverse transcription at $50^{\circ} \mathrm{C}$ for $30 \mathrm{~min}$, and then at $95^{\circ} \mathrm{C}$ for $15 \mathrm{~min}$. As a PCR cycle, denaturation was performed at $94{ }^{\circ} \mathrm{C}$ for $30 \mathrm{~s}$, annealing at $55^{\circ} \mathrm{C}$ for $30 \mathrm{~s}$, and extension at $72{ }^{\circ} \mathrm{C}$ for $1 \mathrm{~min}$ for 40 cycles. Next, nested-PCR was performed using the product obtained by RT-PCR as a template. A total of $10 \mu \mathrm{M}$ primers (Her F2:5'-GTWA TGCTYTGCATWCATGGCT-3' and Her R2:5' AGCCGACGAAATCAATTCTGTC-3') and TaKaRa ExTaq (Takara Bio Inc., Japan) were used. The reaction conditions were: preheating at $95^{\circ} \mathrm{C}$ for $2 \mathrm{~min}, 35$ cycles of denaturation at $94{ }^{\circ} \mathrm{C}$ for $30 \mathrm{~s}$, annealing at $55^{\circ} \mathrm{C}$ for $30 \mathrm{~s}$, and extension at $72^{\circ} \mathrm{C}$ for $30 \mathrm{~s}$ as one amplification cycle, followed by extension at $72{ }^{\circ} \mathrm{C}$ for $5 \mathrm{~min}$. The product of nested-PCR was electrophoresed on a $1.5 \%$ 


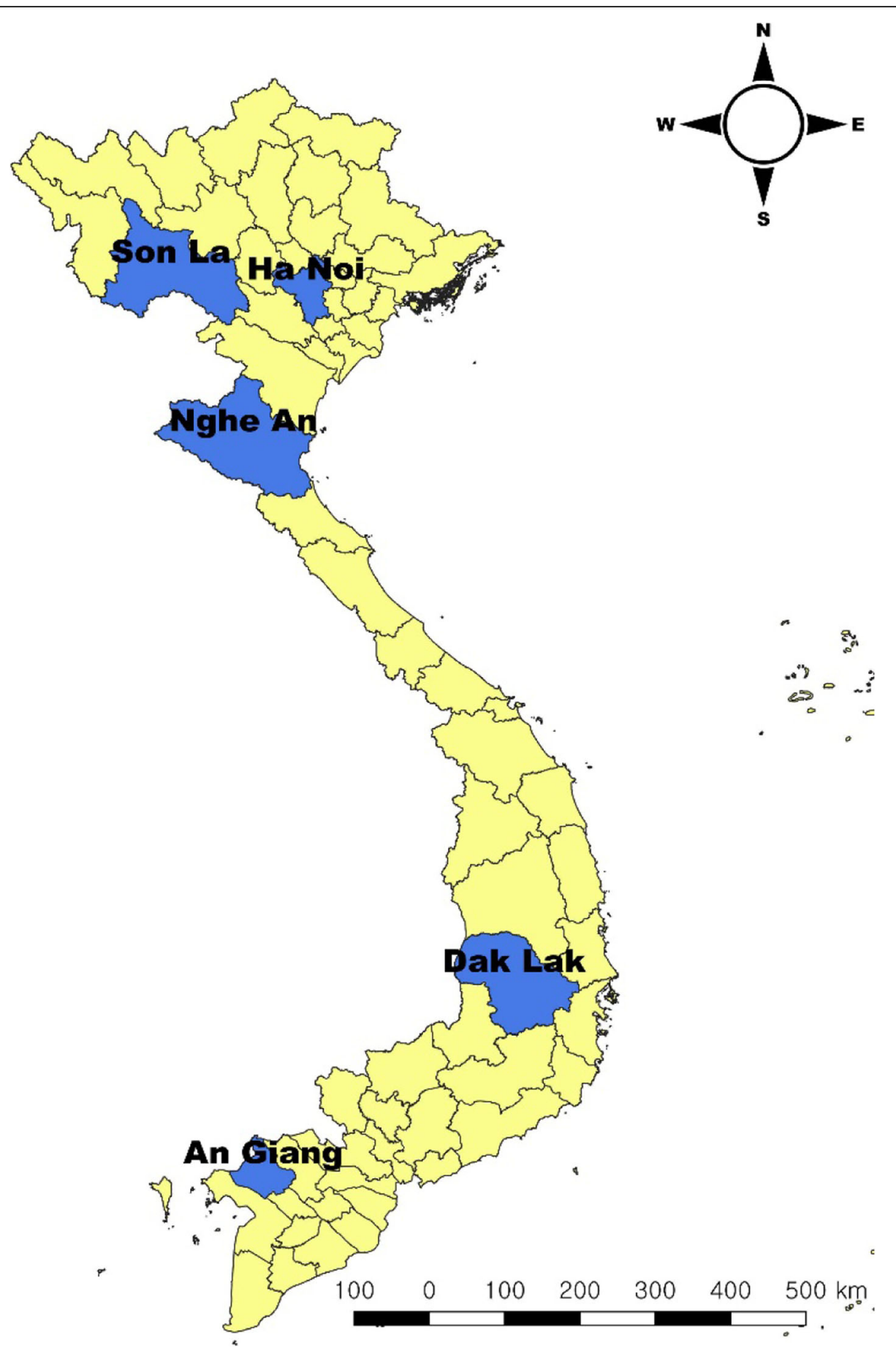

Fig. 3 Five sampling provinces for HEV in pigs in slaughterhouses and farms. ${ }^{*}$ This map was created by our own

agarose gel, and an amplified band of HEV-RNA was detected. The expected amplified band ( $348 \mathrm{bp}$ ) was sequenced after purification.

\section{DNA sequencing}

Two PCR products from each DNA sample were sequenced in both directions using the same nested PCR primers (Her F2, Her R2) by ABI Prism Big Dye Terminator v3.1 Cycle Sequencing Kit (Applied Biosciences, Foster City, CA, USA). The sequences were analyzed by 3500 Genetic Analyzer (Life Technologies, Carlsbad, CA, USA). The consensus sequences were generated from two bidirectional repeats of each sample by software GENETYX Ver.13.0.3 (GENETYX Corp., Tokyo, Japan). 


\section{Data analysis}

We evaluated the true prevalence (TP) of HEV from apparent prevalence (AP) by taking into account the sensitivity and specificity of diagnostic tests using a Bayesian approach [47]. For sera samples, the prior distribution for sensitivity [95 CI\% $(0.683,0.988)]$ and specificity [95\% CI $(0.73,0.99)]$ were estimated from the ELISA experiments. For the TP, a non-informative Jeffreys prior [beta $=(0.5,0.5)]$ was used to minimize the influence on the posterior [48]. For fecal pooled samples, we were not able to calculate the TP because the sensitivity and specificity of PCR were not reported from the previous research experiments. Markov Chain Monte Carlo (MCMC) sampling was implemented by JAGS through the rjags package using the in "truePrev" function in the package prevalence in $\mathrm{R}[49,50]$. The first 1000 samples of the three MCMC chains were discarded as a burn-in period and the following 10,000 iterations were used for posterior inference. The AP was calculated with a $95 \%$ Clopper-Pearson/Exact confidence interval (CI). The TP was estimated based on the posterior median value with a 95\% credible interval. The statistical significance of the differences between prevalence estimates was assessed by examining the overlap of the respective credible intervals. The outputs from the three chains were visually evaluated using MCMC trace-plots, posterior density distribution plots, Brooks-Gelman-Rubin (BGR) plots, and auto-correlation plots using the CODA package [51]. All data were imported into Microsoft Excel 2016 and analyzed using R (version 3.6.2). QGIS (Quantum GIS Development Team 2018. QGIS version number 3.8.3) was used to create the map.

\section{Phylogenetic analysis}

The 348 bp HEV ORF2 nucleotide sequences obtained in this study were aligned using CLUSTALW multiple alignments in BioEdit version 7.2.5. The data compared with worldwide HEV reference strains including all eight genotypes (G1-G8) which were identified in previous study [52]. In addition, phylogenetic analyses were conducted using the Maximum Likelihood (ML) method by MEGA X software [53] with parameter settings of 1000 bootstrap replicates, and the best fit model GTR + G + I.

The same data was utilized to generate ML phylogenetic tree, which was initially used to conduct the Bayesian maximum clade credibility (MCC) host discrete traits tree by using software BEAST v1.8.4 (http://tree. bio.ed.ac.uk/software/beast/). The strict clock and the best fit GTR + G + I nucleotide substitution model with a constant population size coalescent tree prior were used. The MCMC was run at 50,000,000 generations and sampled at every 5000 generations. The effective sample size (ESSs) of the analysis was checked by software Tracer v1.6 (http://tree.bio.ed.ac.uk/software/ tracer/). The MCC host discrete traits output tree was generated by using TreeAnnotator v1.10.4 (http://tree. bio.ed.ac.uk/software/beast/) afterburn 10\% of the first trees. The host phylogenetic tree was reconstructed by software FigTree v.1.4.3 (http://tree.bio.ed.ac.uk/).

\section{Supplementary information}

Supplementary information accompanies this paper at https://doi.org/10. 1186/s12917-020-02537-7.

\section{Additional file 1.}

\section{Abbreviations}

HEV: Hepatitis E virus; NIVR: National institute of veterinary research; ELISA: Enzyme-linked immunosorbent assay; OD: Optical density; RT-PCR: Real time - polymerase chain reaction; TP: true prevalence; AP: apparent prevalence; MCMC: Markov Chain Monte Carlo; BGR: Brooks-Gelman-Rubin; MCC: maximum clade credibility; ESS: effective sample size

\section{Acknowledgments}

The authors thank the National Institute of Veterinary Research (NIVR), Ministry of Agriculture and Rural Development (MARD). The authors also thank the staff of sub-department of animal health from five provinces (An Giang, Dak Lak, Hanoi, Nghe An, Son La) for the collaboration with research team in conducting this study.

\section{Authors' contributions}

Conceived and designed the experiments: HSL, HNV, and $\mathrm{KH}$. Performed the experiments: HSL, DTD, VBN, ANB, DTL, and KH. Analyzed the data: HSL, DTD, KKT, and KH. Wrote the paper: HSL, DTD, SDX, HNV, DG, KKT, and KH. All authors read and approved the final manuscript.

\section{Funding}

This study was funded by the CGIAR Research Program on Livestock and is supported by contributors to the CGIAR Trust Fund. CGIAR is a global research partnership for a food-secure future. This study was also supported by the CGIAR Research Program on Agriculture for Nutrition and Health $(\mathrm{A} 4 \mathrm{NH})$, led by the International Food Policy Research Institute. The funders were not involved in the design of the study and collection, analysis, and interpretation of data and in writing the manuscript.

\section{Availability of data and materials}

The datasets generated and/or analyzed during the current study are available in the GenBank repository, Accession number (MT670024MT670042) to datasets.

\section{Ethics approval and consent to participate}

This study was approved by the Institutional Review Board (IRB) of Hanoi University of Public Health (HUPH), Vietnam (Reference Number IRB/018186/DD-YTCC. Verbal informed consent was obtained from all owners to collect samples from the pigs. The IRB approved verbal informed consent as most of the farmers were either illiterate or semi-literate. This consent form was dated and signed by the researchers indicating that "I have read and explained this consent form to the participant before receiving the participant's consent, and the participant had knowledge of its contents and appeared to understand it".

\section{Consent for publication}

Not applicable.

\section{Competing interests}

The authors declare that they have no competing interests.

\section{Author details}

${ }^{1}$ International Livestock Research Institute (ILRI), Regional Office for East and Southeast Asia, Room 301-302, B1 Building, Van Phuc Diplomatic Compound, 298 Kim Ma Street, Ba Dinh District, Hanoi, Vietnam. ${ }^{2}$ National Institute of 
Veterinary Research, Hanoi, Vietnam. ${ }^{3}$ International Livestock Research Institute (ILRI), Nairobi, Kenya. ${ }^{4}$ Natural Resources Institute, Chatham, UK. ${ }^{5}$ Department of Health Management, Atlantic Veterinary College, University of Prince Edward Island, Charlottetown, Canada. ${ }^{6}$ School of Veterinary Medicine, Rakuno Gakuen University, 582 Bunkyodai, Ebetsu, Hokkaido 069-8501, Japan.

\section{Received: 7 May 2020 Accepted: 23 August 2020}

\section{Published online: 14 September 2020}

\section{References}

1. WHO. Hepatitis E. In: World health organization; 2019. https://www.who.int/ news-room/fact-sheets/detail/hepatitis-e. Accessed 15 Jan 2020.

2. Rein DB, Stevens GA, Theaker J, Wittenborn JS, Wiersma ST. The global burden of hepatitis E virus genotypes 1 and 2 in 2005. Hepatology. 2012;55: 988-97.

3. Smith DB, Izopet J, Nicot F, Simmonds P, Jameel S, Meng X-J, et al. Update: proposed reference sequences for subtypes of hepatitis $E$ virus (species Orthohepevirus A). J Gen Virol. 2020;101(7):jgv001435.

4. Purdy MA, Harrison TJ, Jameel S, Meng XJ, Okamoto H, Van der Poel WHM, et al. ICTV virus taxonomy profile: Hepeviridae. J Gen Virol. 2017;98:2645.

5. Sridhar S, Teng J, Chiu T-H, Lau S, Woo P. Hepatitis E virus genotypes and evolution: emergence of camel hepatitis E variants. Int J Mol Sci. 2017;18: 869.

6. WHO. The Global Prevalence of Hepatitis E Viral Prevalence and Susceptibility. 2010. https://apps.who.int/iris/bitstream/handle/10665/70513/ WHO_IVB_10.14_eng.pdf;jsessionid=EEEB64DB368762563DF98FDEC9F05 7A7? sequence=1. Accessed 7 Jan 2020.

7. Sridhar S, Lau SKP, Woo PCY. Hepatitis E: A disease of reemerging importance. J Formos Med Assoc. 2015;114:681-90.

8. Lee G-H, Tan B-H, Teo EC-Y, Lim S-G, Dan Y-Y, Wee A, et al. Chronic infection with camelid hepatitis $E$ virus in a liver transplant recipient who regularly consumes camel meat and milk. Gastroenterology. 2016;150:355-7.

9. Huang FF, Haqshenas G, Guenette DK, Halbur PG, Schommer SK, Pierson $F W$, et al. Detection by reverse transcription-PCR and genetic characterization of field isolates of swine hepatitis $E$ virus from pigs in different geographic regions of the United States. J Clin Microbiol. 2002;40: $1326-32$.

10. ljaz S, Arnold E, Banks M, Bendall RP, Cramp ME, Cunningham R, et al. Nontravel-associated hepatitis E in England and Wales: demographic, clinical, and molecular epidemiological characteristics. J Infect Dis. 2005;192:116672.

11. Choi I-S, Kwon H-J, Shin N-R, Yoo HS. Identification of swine hepatitis E virus (HEV) and prevalence of anti-HEV antibodies in swine and human populations in Korea. J Clin Microbiol. 2003;41:3602-8.

12. Ge S, Guo Q, Li S, Zhang J, Xia N. Design and preliminary application of a set of highly sensitive universal RT-PCR primers for detecting genotype I/IV hepatitis E virus. Chinese J Virol. 2005;21:181-7.

13. Nishizawa T, Takahashi M, Mizuo H, Miyajima H, Gotanda Y, Okamoto H. Characterization of Japanese swine and human hepatitis $E$ virus isolates of genotype IV with 99\% identity over the entire genome. J Gen Virol. 2003;84: 1245-51.

14. Renou C, Cadranel J-F, Bourlière M, Halfon P, Ouzan D, Rifflet H, et al. Possible zoonotic transmission of hepatitis $\mathrm{E}$ from pet pig to its owner. Emerg Infect Dis. 2007;13:1094.

15. Bouquet J, Cheval J, Rogée S, Pavio N, Eloit M. Identical consensus sequence and conserved genomic polymorphism of hepatitis $E$ virus during controlled interspecies transmission. J Virol. 2012;86:6238-45.

16. Hinjoy S, Nelson KE, Gibbons RV, Jarman RG, Mongkolsirichaikul D, Smithsuwan $P$, et al. A cross-sectional study of hepatitis E virus infection in healthy people directly exposed and unexposed to pigs in a rural community in northern Thailand. Zoonoses Public Health. 2013;60:555-62.

17. Pauly M, Muller CP, Black AP, Snoeck CJ. Intense human-animal interaction and limited capacity for the surveillance of zoonoses as drivers for Hepatitis E virus infections among animals and humans in Lao PDR. Int J Infect Dis. 2016;53:18.

18. Conlan JV, Jarman RG, Vongxay K, Chinnawirotpisan P, Melendrez MC, Fenwick S, et al. Hepatitis E virus is prevalent in the pig population of Lao People's Democratic Republic and evidence exists for homogeneity with Chinese Genotype 4 human isolates. Infect Genet Evol. 2011;11:1306-11.
19. Corwin AL, Khiem HB, Clayson ET, Sac PK, Nhung VTT, Yen VT, et al. A waterborne outbreak of hepatitis $\mathrm{E}$ virus transmission in southwestern Vietnam. Am J Trop Med Hyg. 1996;54:559-62.

20. Berto A, Pham HA, Thao TTN, Vy NHT, Caddy SL, Hiraide R, et al. Hepatitis E in southern Vietnam: Seroepidemiology in humans and molecular epidemiology in pigs. Zoonoses Public Health. 2018;65:43-50.

21. Hoan NX, Huy PX, Sy BT, Meyer CG, Son T Van, Binh MT, et al. High Hepatitis E virus (HEV) Positivity Among Domestic Pigs and Risk of HEV Infection of Individuals Occupationally Exposed to Pigs and Pork Meat in Hanoi, Vietnam. In: Open forum infectious diseases. Oxford University Press US; 2019. p. ofz306.

22. Liu X, Saito M, Sayama Y, Suzuki E, Malbas FF, Galang HO, et al. Seroprevalence and molecular characteristics of hepatitis $E$ virus in household-raised pig population in the Philippines. BMC Vet Res. 2015;11:11.

23. Takahashi M, Nishizawa T, Tanaka T, Tsatsralt-Od B, Inoue J, Okamoto H. Correlation between positivity for immunoglobulin A antibodies and viraemia of swine hepatitis E virus observed among farm pigs in Japan. J Gen Virol. 2005;86:1807-13.

24. Krumbholz A, Joel S, Neubert A, Dremsek P, Dürrwald R, Johne R, et al. Agerelated and regional differences in the prevalence of hepatitis $E$ virusspecific antibodies in pigs in Germany. Vet Microbiol. 2013;167:394-402.

25. Martinelli N, Luppi A, Cordioli P, Lombardi G, Lavazza A. Prevalence of hepatitis $\mathrm{E}$ virus antibodies in pigs in Northern Italy. Infect Ecol Epidemiol. 2011;1:7331.

26. Blacksell SD, Myint KSA, Khounsy S, Phruaravanh M, Mammen MP Jr, Day NPJ, et al. Prevalence of hepatitis E virus antibodies in pigs: implications for human infections in village-based subsistence pig farming in the Lao PDR. Trans R Soc Trop Med Hyg. 2007;101:305-7.

27. Di Bartolo I, Ponterio E, Castellini L, Ostanello F, Ruggeri FM. Viral and antibody HEV prevalence in swine at slaughterhouse in Italy. Vet Microbiol. 2011;149:330-8.

28. de Oya NJ, de Blas I, Blázquez A-B, Martín-Acebes MA, Halaihel N, Gironés O, et al. Widespread distribution of hepatitis $E$ virus in Spanish pig herds. BMC Res Notes. 2011:4:412.

29. Hinjoy S, Nelson KE, Gibbons RV, Jarman RG, Chinnawirotpisan P, Fernandez S, et al. A cross-sectional study of hepatitis $E$ virus infection in pigs in differentsized farms in northern Thailand. Foodborne Pathog Dis. 2013;10:698-704.

30. Keawcharoen J, Thongmee T, Panyathong R, Joiphaeng P, Tuanthap S, Oraveerakul $\mathrm{K}$, et al. Hepatitis $\mathrm{E}$ virus genotype $3 \mathrm{f}$ sequences from pigs in Thailand, 2011-2012. Virus Genes. 2013;46:369-70.

31. Yazaki Y, Mizuo H, Takahashi M, Nishizawa T, Sasaki N, Gotanda Y, et al. Sporadic acute or fulminant hepatitis $E$ in Hokkaido, Japan, may be foodborne, as suggested by the presence of hepatitis $E$ virus in pig liver as food. J Gen Virol. 2003;84:2351-7.

32. Intharasongkroh D, Sa-nguanmoo P, Tuanthap S, Thongmee T, Duang-in A, Klinfueng $S$, et al. Hepatitis E virus in pork and variety meats sold in fresh markets. Food Environ Virol. 2017;9:45-53.

33. Slot E, Zaaijer HL, Molier M, Van den Hurk K, Prinsze F, Hogema BM. Meat consumption is a major risk factor for hepatitis $E$ virus infection. PLoS One. 2017;12:e0176414.

34. Liu P, Li L, Wang L, Bu Q, Fu H, Han J, et al. Phylogenetic analysis of 626 hepatitis $E$ virus (HEV) isolates from humans and animals in China (19862011) showing genotype diversity and zoonotic transmission. Infect Genet Evol. 2012;12:428-34.

35. Sato $Y$, Sato $H$, Naka K, Furuya $S$, Tsukiji $H$, Kitagawa $K$, et al. A nationwide survey of hepatitis E virus (HEV) infection in wild boars in Japan: identification of boar HEV strains of genotypes 3 and 4 and unrecognized genotypes. Arch Virol. 2011;156:1345-58.

36. Wu J, Chen C, Chiang T, Tsai W, Jeng W, Sheen I, et al. Spread of hepatitis E virus among different-aged pigs: two-year survey in Taiwan. J Med Virol. 2002;66:488-92.

37. Kim S-E, Kim M-Y, Kim D-G, Song Y-J, Jeong H-J, Lee S-W, et al. Determination of fecal shedding rates and genotypes of swine hepatitis $E$ virus (HEV) in Korea. J Vet Med Sci. 2008;70:1367-71.

38. Sonoda $H$, Abe M, Sugimoto $T$, Sato $Y$, Bando M, Fukui E, et al. Prevalence of hepatitis $E$ virus (HEV) Infection in wild boars and deer and genetic identification of a genotype 3 HEV from a boar in Japan. J Clin Microbiol. 2004:42:5371-4

39. Lu Y-H, Qian H-Z, Hu A-Q, Ren H, Qin X, Jiang Q-W, et al. Duration of viraemia in Chinese acute sporadic hepatitis E. Eur J Clin Microbiol Infect Dis. 2014;33:755-9. 
40. (CEMA) CFEMA. Committee For Ethnic Minority Afairs (CEMA). 2020. http:// english.ubdt.gov.vn/referencepage/ethnic-committee-with-local.htm. Accessed 15 Mar 2020

41. Nguyen XTT, Nguyen TTT, Nguyen-Viet H, Tran KN, Lindahl J, Grace Randolph D, et al. Assessment of aflatoxin B1 in maize and awareness of aflatoxins in Son La, Vietnam. Infect Ecol Epidemiol. 2018;8:1553464.

42. Dosman DM, Adamowicz WL, Hrudey SE. Socioeconomic determinants of health-and food safety-related risk perceptions. Risk Anal. 2001;21:307-18.

43. Malhotra R, Lal P, Krishna Prakash S, Daga MK, Kishore J. Evaluation of a health education intervention on knowledge and attitudes of food handlers working in a medical college in Delhi, India. Asia Pacific J Public Heal. 2008; 20:277-86.

44. Van Dongen S. Prior specification in Bayesian statistics: three cautionary tales. J Theor Biol. 2006;242:90-100.

45. Dorny P, Phiri IK, Vercruysse J, Gabriël S, Willingham lii AL, Brandt J, et al. A Bayesian approach for estimating values for prevalence and diagnostic test characteristics of porcine cysticercosis. Int J Parasitol. 2004;34:569-76.

46. Lee HS, Lindahl J, Nguyen-Viet H, Khong NV, Nghia VB, Xuan HN, et al. An investigation into aflatoxin $\mathrm{M} 1$ in slaughtered fattening pigs and awareness of aflatoxins in Vietnam. BMC Vet Res. 2017;13:363.

47. Messam LLM, Branscum AJ, Collins MT, Gardner IA. Frequentist and Bayesian approaches to prevalence estimation using examples from Johne's disease. Anim Heal Res Rev. 2008;9:1-23.

48. Jeffreys H. An invariant form for the prior probability in estimation problems. Proc R Soc Lond A. 1946;186:453-61.

49. Plummer M. JAGS: Just another Gibbs sampler; 2004

50. Devleesschauwer B, Torgerson P, Charlier J, Levecke B, Praet N, Roelandt S, et al. Package 'prevalence.' 2015.

51. Plummer M, Best N, Cowles K, Vines K. CODA: convergence diagnosis and output analysis for MCMC. R news. 2006;6:7-11.

52. Hall TA. BioEdit: a user-friendly biological sequence alignment editor and analysis program for Windows 95/98/NT. In: Nucleic acids symposium series, [London]: Information Retrieval Ltd., c1979-c2000.; 1999. p. 95-8.

53. Kumar S, Stecher G, Li M, Knyaz C, Tamura K. MEGA X: molecular evolutionary genetics analysis across computing platforms. Mol Biol Evol. 2018:35:1547-9.

\section{Publisher's Note}

Springer Nature remains neutral with regard to jurisdictional claims in published maps and institutional affiliations.

Ready to submit your research? Choose BMC and benefit from:

- fast, convenient online submission

- thorough peer review by experienced researchers in your field

- rapid publication on acceptance

- support for research data, including large and complex data types

- gold Open Access which fosters wider collaboration and increased citations

- maximum visibility for your research: over $100 \mathrm{M}$ website views per year

At $\mathrm{BMC}$, research is always in progress.

Learn more biomedcentral.com/submissions 